кандидат юридических наук, доцент, доцент кафедры земельного, трудового и экологического права

Кубанского государственного

аграрного университета имени И.Т. Трубилина

\section{МЕЖДУНАРОДНЫЕ АКТЫ И ЗАРУБЕЖНЫЙ ОПЫТ ПО ВОПРОСАМ РЕГУЛИРОВАНИЯ ТРУДА ИНОСТРАННЫХ ГРАЖДАН}

PhD in Law Associate Professor Land, Labor and Environmental Law Department Kuban State Agrarian University

\section{INTERNATIONAL INSTRUMENTS AND INTERNATIONAL PRACTICE REGARDING THE INTERNATIONAL LABOR REGULATION}

Аннотация:

В статье рассматриваются основные междуна родные акты, регулирующие вопросы трудовой миграции, в частности конвенции МОТ, касающи еся дискриминации трудовых мигрантов и защить их прав. Автор анализирует законодательство России в сравнении с международными актами, а также законодательство стран, в которых накоплен значительный опыт правового регулирования труда мигрантов. Актуальность темы обусловлена принятием летом 2018 г. Генеральной Ассамблеей ООН окончательного проекта глобального договора в сфере трудовой миграции, в котором е качестве цели указано сдерживание нелегальной миграции. Анализируя законодательство Франции, Германии и США, основных стран-лидеров в сфере трудовой миграции, а также Китая, автор приходит к выводам о взачмосвязи правового регулирования миграционных процессов с ситуацией на рынке труда и необходимостью защиты национальных интересов страны.

Ключевые слова:

миграция, конвенция, труд, трудовая миграция, международный обычай, дискриминация, защита прав.
Summary:

The research examines the main international instruments that regulate the labor migration issues, in particular the ILO Conventions on the discrimination against labor migrants and the protection of their rights. At the same time, the author analyzes the Russian legislation in comparison with the international acts as well as the legislation of countries which have considerable experience in the legal regulation of labor migration. The relevance of the study is determined by the final draft of a global treaty on labor migration aimed at containing illegal migration and adopted by the UN General Assembly in summer of 2018. Having analyzed the legislation of France, Germany, the USA, China and the basic leading countries in the field of labor migration, the author concludes that there are the relationships between the legal regulation of migration processes with the labor market situation and the need to protect the national interests of the country.

Keywords:

migration, convention, labor, labor migration, international custom, discrimination, protection of rights.

Международные акты, которые были ратифицированы страной, обязывают ее привести национальное законодательство в соответствие. Это способствует унификации правового регулирования трудовых отношений в различных странах, имеющих весьма разнообразное законодательство.

Базовыми положениями в регулировании трудовой миграции в международном частном праве являются следующие:

- соблюдение прав человека;

- обязанность государства принимать граждан, которые возвращаются в страну;

- обязанность государства предоставить доступ к консульству нерезидентов;

- борьба с незаконным въездом в страну мигрантов;

- соблюдение международных соглашений, подписанных страной.

Имеется два источника международного частного права, которые считаются основой международного трудового законодательства: международные договоры и международные обычаи.

Можно увидеть терминологическое разнообразие в названиях международного договора: «конвенция», «международный договор», «пакт», «устав», «декларация», «манифест» и др. Названные термины применяются к соглашениям, которые заключаются письменно различными государствами для регулирования вопросов труда. Для них характерна обязанность сторон совершать определенные соглашением действия и выполнять взятые обязательства.

Международные обычаи применяются, по общему правилу, когда отношения не урегулированы международным договором. Международные обычаи представляют собой правила, складывающиеся в результате длительного применения между двумя и более государствами, когда конкретный вид отношений не был урегулирован международным договором. 
Венская Конвенция о праве международных договоров от 23.05.1969 [1] устанавливает правило, по которому нормы, содержащиеся в договоре, могут стать обязательными для применения третьими странами в качестве обычной нормы международного права, при условии признания ее таковой (ст. 38).

Формулировка ст. 38 Венской конвенции может трактоваться по-разному. На наш взгляд, если государство не признало норму в качестве обычной, она не может стать для него обязательной. Необходимо помнить при этом, что имеется общее правило, по которому договор не может создавать правил и обязательств для третьих государств.

Специалисты-международники уделяют большое внимание обычаю [2], который следует отличать от международного обыкновения. Международное право рассматривает нарушение международного обычая как правонарушение, в отличие от нарушения международного обыкновения.

За пределами России правовое регулирование труда мигрантов, как правило, осуществляется законодательством страны пребывания. Среди источников законодательства можно назвать национальное законодательство принимающей страны, международные нормы и международные обычаи.

Вопросы международной трудовой миграции нашли соответствующее отражение в Конвенции № 97 [3], принятой Международной организацией труда (пересмотрена в 1949 г.). В ней сказано, что «работник-мигрант» - это лицо, выезжающее из одной страны в другую, имея намерение получить работу иначе, чем за собственный счет, а также сюда включается любое лицо, допускаемое по закону в качестве работника-мигранта (ст. 11). В эту группу не входят работники пограничной службы, лица, мигрирующие краткосрочно, к примеру моряки и т. п.

Каждая страна, ратифицировавшая конвенцию, должна «предоставлять без всякой дискриминации (в отношении таких признаков, как национальность, религия, раса или пол иммигранта) на законном основании находящимся на его территории те же условия, которыми наделены граждане принимающей стороны» (ст. 6).

Важными международными актами являются Конвенции МОТ № 118 (1962), № 143 (1975) и др.

Генеральная Ассамблея ООН в 1990 г. приняла Международную конвенцию о защите прав работников-мигрантов, а также их семей [4] с целью обеспечения надлежащей защиты не только самого работника, но и тех членов его семьи, которые выезжают вместе с ним (резолюция 45/158).

В ст. 1 Конвенции говорится, что дискриминация трудовых мигрантов по любому признаку является незаконной, впервые упоминаются «члены их семей». Вопрос о членах семьи мигранта не нашел своего отражения в законодательстве России на данном этапе. Имеется упоминание о выдаче виз членам семьи высококвалифицированного работника в Федеральном законе от 15.08.1996 № 114-Ф3 [5] (ст. 13.2). Специальный правовой статус высококвалифицированного специалиста в данном случае распространяется и на членов его семьи. Например, они освобождаются от сдачи экзамена на знание русского языка.

По истечении срока действия Программы сотрудничества между Россией и МОТ на 20132016 гг. [6] была разработана и подписана 21 ноября 2016 г. в Москве новая программа такого сотрудничества на 2017-2020 гг. [7]. Как сказано в Программе, развитие социально-трудовых отношений в России должно осуществляться в направлении достижения и реализации принципов достойного труда. В качестве основных приоритетов, определенных для сотрудничества между РФ и МОТ на 2017-2020 гг., намечено осуществить: расширение возможностей занятости и возможностей повышения производительности труда, принятие мер, направленных на обеспечение соблюдения норм на всех рабочих местах, и создание достойных условий труда. Также в Программе предусматривалось сотрудничество в сфере социального страхования, пенсионного обеспечения, меры по продвижению международных трудовых норм, усилия для укрепления социального диалога. Можно увидеть определенную динамику развития законодательства о миграции в России, хотя некоторые авторы отмечают, что миграционная политика России находится в переходном периоде [8].

Концепция миграционной политики России на период до 2025 г. [9] констатирует, что опыт стран, проводящих активную миграционную политику, показывает ускорение их социально-экономического развития и рост благосостояния населения за счет проходящих миграционных процессов (ст. 19).

Согласно последним оценкам ДЭСВ ООН, число международных мигрантов в мире достигло 258 млн человек в 2017 г., увеличившись почти на 50 \% с 2000 г. [10].

Генеральная Ассамблея ООН, признавая важность миграционных процессов, приняла меры по подготовке глобального договора в данной сфере. Летом 2018 г. был достигнут консенсус в отношении окончательного проекта глобального договора [11] для обеспечения безопасной, упорядоченной и регулярной миграции. Этот договор является основой для международного сотрудничества в решении проблем миграции во всех ее аспектах. В соответствии с проектом договора, основной целью является содействие безопасной, упорядоченной и законной миграции, а также сдерживание распространения и воздействия нелегальной миграции. Договор 
направлен на защиту безопасности, достоинства и прав человека и основных свобод всех мигрантов. Общественная безопасность, как более широкая категория, является необходимым условием существования человеческого общества [12, с. 10].

Безусловными лидерами в вопросах миграции являются страны EC: Великобритания, Германия, Франция - и страна классической миграции - США. Эти страны являются наиболее предпочтительными для трудящихся-мигрантов, в том числе из России.

На современное российское трудовое законодательство и правоприменительную практику оказывают существенное влияние зарубежный опыт и международные трудовые стандарты.

КНР. В Китайской Народной Республике действует закон КНР о въезде и выезде от 2013 г. [13], в соответствии с которым (ст. 8) иностранцы, направляющиеся в Китай на работу по приглашению или по найму, при обращении за визой должны иметь на руках соответствующие свидетельства о приглашении или найме. По законодательству Китая, иностранец - это лицо, не обладающее гражданством Китая в соответствии с положениями «Закона Китайской Народной Республики о гражданстве». Согласно данному закону, иностранцу, который приехал в Китай на работу, и сопровождающим его членам семьи выдается особая виза категории «Z».

Иностранцы, работающие в Китае, обязаны иметь разрешение на работу и вид на жительство. Ни организация, ни частное лицо не могут нанять иностранного гражданина для работы без этих двух документов (ст. 41).

В законодательстве КНР имеются критерии, по которым трудовая деятельность иностранного работника признается нелегальной со всеми вытекающими последствиями. Например, нелегальной будет работа без наличия разрешения и рабочего вида на жительство, работа за рамками сореры деятельности, которая была установлена в разрешениях на работу. Если, являясь иностранным студентом, трудовой мигрант нарушает административные положения при совмещении работы с учебой и выходит за рамки оговоренной сферы деятельности или нарушает временной лимит, работа тоже будет признана нелегальной (ст. 43).

Те подразделения, которые берут на работу иностранцев, должны сообщать информацию в органы общественной безопасности, так как это обязательное требование (ст. 45). Незаконная занятость в Китае влечет за собой депортацию.

На иностранца, который работает нелегально (ст. 80), налагается штраф, размер которого достаточно высок: от 5000 до 20000 юаней [14]. При наличии серьезных обстоятельств возможно задержание на срок от 5 до 15 суток и размер штрафа увеличивается до 20000 юаней. Лица, способствующие незаконной занятости, также несут ответственность в виде штрафра. Получение незаконных заработков за счет незаконной занятости может привести к их конфискации.

По количеству проживающих мигрантов в числе первых находятся США, Саудовская Аравия, Германия и Россия. Больше всего мигрантов, по данным ООН, проживает в США - 49,8 млн человек. В Саудовской Аравии и Германии проживают по 12,2 млн мигрантов. Россия находится на четвертом месте, в ней проживают 11,7 млн мигрантов [15].

Значительный опыт правового регулирования потоков внешней трудовой миграции принадлежит Великобритании, Германии, США, Франции. Великобритания и США относятся к семье англосаксонского, или общего, права, Франция и Германия - к романо-германской правовой семье.

Великобритания. Демографический кризис привел к уменьшению работоспособного населения и увеличению числа лиц пожилого возраста. Повысить рождаемость весьма проблематично, и поэтому трудовые мигранты обеспечивали необходимое количество рабочих рук. В 1920-е гг. была введена система выдачи разрешений на работу (Work Permits) для иностранцев, целью которой было обеспечение выборочного приема иностранцев в стране. Выбор производился по определенным категориям работников в зависимости от профессиональных и квалификационных данных последних [16]. Таким образом, мигранты удовлетворяли спрос на рабочую силу, сформировавшийся на рынке труда в тех местах, где по разным причинам не желали работать граждане страны. Позже появляется строгая привязка работника-мигранта к определенному работодателю.

Действуют акты «Об иммиграции» от 1971 г. и 1988 г. (The Immigration Act) [17], которые содержат правила въезда и пребывания в стране. Лицо считается совершившим преступление, если работает в то время, когда не имеет такого права по причине своего статуса или отстранения от работы.

США. На сегодняшний день США ратифицировали только 14 конвенций МОТ. Всего одна из них направлена на обеспечение защиты прав всех работников. Это Конвенция МОТ № 105 (1957), которая посвящена запрещению принудительного труда. В США до настоящего времени не ратифицировали конвенции, касающиеся труда мигрантов, так как настроены на установление собственных стандартов в данной сфере. Имеется внутреннее законодательство США, касающееся труда мигрантов. Так, акты миграционного законодательства включены в главы Свода законов США [18], в котором имеются главы, посвященные миграции. 
Франция. В стране имеется внутреннее законодательство, например ордонанс 45-2658 от 2 ноября 1945 г. «Об условиях въезда и пребывания иностранцев во Франции», который ныне отменен в связи с кодификацией законодательства. Значительная часть правовых актов сведена в Кодекс въезда и пребывания иностранцев и права на убежище [19]. Также в стране действует закон Франции № 2006-911 от 24 июля 2006 г. «Об иммиграции и интегрировании» [20]. Обращает на себя внимание наличие кодифицированного акта, что, на наш взгляд, не только концентрирует и объединяет нормы о труде иностранных граждан, но и облегчает правоприменение. Создание такого документа в России было бы весьма целесообразно.

Германия. Значительная часть положений о трудоустройстве иностранных граждан закреплена в законе «О въезде и пребывании иностранцев на территории ФРГ» [21]. Некоторые уточнения имеются в постановлении правительства «О выдаче разрешения на работу лицам, не являющимся гражданами ФРГ» от 1971 г., а также в постановлении правительства «О реализации Закона об иностранцах» от 1990 г. [22, с. 95]. Таким образом, труд иностранцев регулируется правовыми средствами.

Все развитые страны Западной Европы и США на протяжении последних лет принимали меры для привлечения квалифицированных мигрантов, что нашло отражение в их законодательстве, наиболее благоприятном для таких мигрантов.

В качестве общего вывода можно сказать, что все страны стремятся урегулировать вопросы миграции различными правовыми средствами, выбор которых напрямую связан с защитой национальных интересов в вопросах трудоустройства и зависит от ситуации, сформировавшейся на рынке труда. Важную роль в унификации законодательства, касающегося миграции, играют конвенции МОТ, которые, к сожалению, не были еще ратифицированы в России, но содержание которых учитывается в национальном законодательстве.

\section{Ссылки и примечания:}

1. Венская Конвенция о праве международных договоров от 23 мая 1969 г. // Ведомости ВС СССР. 1986. № 37. Ст. 772.

2. Kopelmanas L. Custom as a Means of the Greation of International Law // BYIL. 1937 ; Kunz J.L. The Nature of Customary International Law // American Journal of International Law. 1953. Vol. 47, no. 4. P. 662-669. https://doi.org/10.2307/2194914 ; Wolfke K. Custom in Present International Law. Wroclow, 1964.

3. О трудящихся-мигрантах : конвенция № 97 Международной организации труда от 24 июня 1975 г. : пересмотр. в 1949 г. // Конвенции и рекомендации, принятые Международной конференцией труда. 1919-1956. Т. І. Женева, 1991. C. $965-981$.

4. Международная конвенция о защите прав всех трудящихся-мигрантов и членов их семей от 18 дек. 1990 г. // Советский журнал международного права. 1991. № 3-4. С. 136-172.

5. О порядке выезда из Российской Федерации и въезда в Российскую Федерацию : федер. закон от 15 авг. 1996 г. № 114-Ф3 : ред. От 19 февр. 2018 г. // СЗ РФ. 1996. № 34. Ст. 4029.

6. Программа сотрудничества между Российской Федерацией и Международной организацией труда на 2013-2016 годы : принята в Москве 11 дек. 2012 г. // Бюллетень трудового и социального законодательства Российской Федерации. 2013. № 3. С. 126-133.

7. Программа сотрудничества между Российской Федерацией и Международной организацией труда на 2017-2020 гг. подписана в Москве 21 нояб. 2016 г. // Там же. 2017. № 12.

8. Кобылинская С.В. Современная миграционная политика России [Электронный ресурс] // Научный журнал КубГАУ. 2014. № 103 (09). URL: http://ej.kubagro.ru/2014/09/pdf/70.pdf (дата обращения: 18.08.2018).

9. Концепция государственной миграционной политики Российской Федерации на период до 2025 года. Доступ из справ.-правовой системы «КонсультантПлюс».

10. Landmark agreement on Global Compact \#ForMigration [Электронный pecypc]. URL: https://www.un.org/development/desa/undesavoice/highlights/2018/08\#41427 (дата обращения: 18.08.2018)

11. Global compact for safe, orderly and regular migration 29.06.2018 [Электронный pecypc]. URL: https://www.un.org/pga/72/wp-content/uploads/sites/51/2018/06/PGA-Letter-Transmission-of-Draft-Rev-3-Global-CompactMigration.pdf (дата обращения: 18.08.2018)

12. Глушко О.А. Теоретические предпосылки формирования концепции общественной безопасности // Очерки новейшей камералистики. 2014. № 1. С. 10-13.

13. Закон KHР о въезде и выезде [Электронный ресурc]. URL: http://www.asia-business.ru/law/law2/foreigner/entry/ (дата обращения: 18.08.2018).

14. Примерно от 47605 до 190000 р. по курсу на 8 августа 2018 г.

15. ООН: более четверти миллиарда человек в мире являются мигрантами [Электронный pecypc]. URL: http://tass.ru/mezhdunarodnaya-panorama/4823149 (дата обращения: 18.08.2018).

16. Правовое регулирование миграции в Великобритании: история и современность [Электронный ресурc]. URL: http://www.eurasialegal.info/index.php?option=com_content\&view=article\&id=3002:2013-12-06-09-43-20\&catid=141:201207-02-12-20-07 (дата обращения: 18.08.2018).

17. Immigration Act 1971 [Электронный ресурc]. URL: http://www.legislation.gov.uk/ukpga/1971/77/contents (дата обращения: 18.08.2018). Закон об иммиграции 1971, раздел 24В, обновлен со всеми изменениями, которые, как известно, вступили в силу 8 августа 2018 г. Существуют изменения, которые могут быть введены в действие в будущем.

18. The Code of the Laws of the United States of America [Электронный pecypc]. URL: https://www.law.cornell.edu/uscode/text (дата обращения: 18.08.2018).

19. Code de l'entrée et du séjour des étrangers et du droit d'asile. Version consolidée au 6 août 2018.

20. Законодательные акты Франции и Швейцарии 2005-2006 гг. об иммиграции и интеграции : сборник / пер.-сост. д-р юрид. наук И.В. Понкин. М., 2008. 101 с. ; Loi $\mathrm{n}^{\circ}$ 2006-911 du 24 juillet 2006 relative à l'immigration et à l'intégration. 
21. Das Gesetz über die Einreise und den Aufenthalt von Ausländern im Bundesgebiet [Электронный pecypc]. URL: https://www.bgbl.de/xaver/bgbl/start.xav?startbk=Bundesanzeiger_BGBI\&jumpTo=bgbl190s1354.pdf\#_bgbl_\%2F\%2F*\%5B\%40attr_id\%3D\%27bgbl190s 1354.pdf\%27\%5D_1534318 586569 (дата обращения: 18.08.2018).

22. Погорельская С.В. Прощание с мультикультурализмом, или Новая германская иммиграционная политика // Актуальные проблемы Европы. М., 2006. № 1. С. 95.

\section{References:}

Code de l'entrée et du séjour des étrangers et du droit d'asile. Version consolidée au 6 août 2018 2018, (in French).

Das Gesetz über die Einreise und den Aufenthalt von Ausländern im Bundesgebiet 2018, viewed 18 August 2018, $<$ https://www.bghl.de/xaver/bgbl/start.xav?startbk=Bundesanzei-

ger_BGBI\&jumpTo=bgbl190s1354.pdf\#_bgbl_\%2F\%2F*5B\%40attr_id\%3D\%27bgbl190s1354.pdf\%27\%5D_15343185865

69>, (in German).

Global Compact for Safe, Orderly and Regular Migration dated June 29, 2018 2018, viewed 18 August 2018, <https://www.un.org/pga/72/wp-content/uploads/sites/51/2018/06/PGA-Letter-Transmission-of-Draft-Rev-3-Global-Compact-Migration.pdf>.

Glushko, OA 2014, 'Theoretical Backgrounds to the Development of the Concept of Public Security', Ocherki noveyshey kameralistiki, no. 1, pp. 10-13, (in Russian)

Immigration Act 1971 2018, viewed 18 August 2018, <http://www.legislation.gov.uk/ukpga/1971/77/contents>

Kobylinskaya, SV 2014, 'The Modern Migration Policy of Russia', Nauchnyy zhurnal KubGAU, no. 103 (09), viewed 18 August 2018, <http://ej.kubagro.ru/2014/09/pdf/70.pdf>, (in Russian).

Kopelmanas, L 1937, 'Custom as a Means of the Creation of International Law', BYIL.

Kunz, JL 1953, 'The Nature of Customary International Law', American Journal of International Law, vol. 47, no. 4, pp. 662669. https://doi.org/10.2307/2194914.

Landmark Agreement on Global Compact \#ForMigration viewed 18 August 2018, <https://www.un.org/development/desa/undesavoice/highlights/2018/08\#41427>.

Loi $n^{\circ}$ 2006-911 du 24 juillet 2006 relative à l'immigration et à l'intégration 2018, (in French).

Pogorelskaya, SV 2006, 'Farewell to Multiculturalism, or New German Immigration Policy', Aktual'nyye problemy Yevropy, Moscow, no. 1, p. 95, (in Russian).

Ponkin, IV (comp.) (transl.) 2008, Legislative Acts of France and Switzerland of 2005-2006 on Immigration and Integration, compilation, Moscow, 101 p., (in Russian).

The Code of the Laws of the United States of America 2018, viewed 18 August 2018, <https://www.law.cornell.edu/uscode/text>.

Wolfke, K 1964, Custom in Present International Law, Wroclaw. 